\title{
Behavior of photopolymer fiber structures in microgravity
}

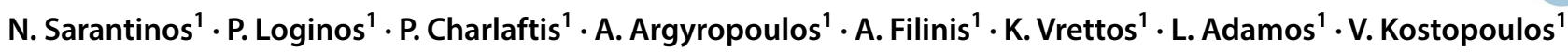

Received: 28 March 2019 / Accepted: 4 November 2019 / Published online: 27 November 2019

(c) Springer Nature Switzerland AG 2019

\begin{abstract}
Tackling the need of more research on the field of space deployable structures, this study aims to explore the concept of space manufacturing. The target is to acquire insight that shall be useful for future deep space missions, where the in situ production of components and repair procedures shall be mission critical. In particular, the objective of this study was to deploy and cure, pneumatically actuated fiber reinforced UV polymer beam structures in micro-gravity. Then, the specimens were tested in the laboratory to identify the effects of micro-gravity on the microstructure, macrostructure, thermal and mechanical behavior of the composite material, by comparing the 0-g specimens with a 1-g control group. This research was performed by participation in the ESA-European Space Agency Fly Your Thesis! 2017 programme and the 68th ESA Parabolic Flight Campaign, through which, access to the Novespace's Zero-G aircraft laboratory was allowed.
\end{abstract}

Keywords Glass fibers · Cure behavior · Mechanical testing · Microstructural analysis · UV polymers · Microgravity

\section{Introduction}

The idea of using UV polymers for space application is not new, it was first conceived and prototype tested during the Space Race in 1963, for use in space inflatable structures by the Hughes Aircraft Company [1]. Inflatable booms were deployed by pneumatic or foam-driven techniques and then cured using internal UV Ledstrips or solar radiation. The inflatable booms were made of fibre cloths preimpregnated with UV Polymers.

Since then, several research projects on the use of different materials in space has been performed throughout time. However, a few researches have been performed on the behavior of polymers, especially the curing procedure, in the space environment-vacuum and microgravity. Research on the behavior of materials in vacuum chambers measuring outgassing has been performed for a wide variety of materials by NASA [2]. On the other hand, research on the behavior of polymer materials cured in microgravity has not been extensively performed. The main difficulty for research on that field is that the curing of polymers requires time ranges that measure to hours for polymerization and the only lab capable of providing that long micro-gravity time ranges is the International Space Station. However, experimenting on polymerization requires high-temperatures, which are a critical concern in the ISS. On the other hand, UV polymerizing polymers could be cured in seconds and without high-temperature need or generation, thus making them capable of being experimented to in a parabolic flight campaign [3-5].

There has been investigation of the idea of deployables previously in literature, and also in the Fly Your Thesis! campaign. "Spaghetti Tubes", a project participation in the Fly Your Thesis! campaign in 2003 investigated the use of inflatable deployable tubes [6]. Additionally, in 2004 a project named "Composite Photopolymerization for Teeth Repairing" flew on the campaign [7], which was focused on the effects of microgravity on photo-polymerizing medical polymers. Finally, the 2011 ESA REXUS project "FOCUS" experiment [8] flew on a suborbital rocket flight, where a deployable structure was inflated and cured, to investigate the feasibility of space manufacturing.

\footnotetext{
$\triangle$ V. Kostopoulos, kostopoulos@upatras.gr|' Applied Mechanics Laboratory (Space Group)/Mechanical Engineering and Aeronautics Department, University of Patras, Patras, Greece.
} 


\section{Scientific background}

In recent years, the use of polymers in space structures is being investigated, in order to extent the list of spacegraded materials for space applications [9]. Polymers are ideal space materials as they are lightweight and can be reinforced with fibre cloths, manufacturing composite materials that can reach mechanical properties higher than of metals [10]. Also, photopolymers could find potential applications in the new space era, as binders or matrices in composite materials created through ISRU—In-Situ Resource Utilization techniques, which could serve as potential habitation modules in planetary settlements on the Moon or Mars. Also, the possibility of using photopolymers in the recycling techniques of space structures, for re-usage of derelict satellites or even space trash in repairing applications or even as base structural material [11].

The advantages of UV polymers as matrices in composite materials is primarily the curing time, which could take place within seconds and using the solar radiation as the curing agent which eliminates the need of an energy source. Furthermore, UV polymers are cured in lower temperatures than convectional polymers used as composite matrices, which significantly lowers thermal stresses in fibre reinforced composites. Finally, UV polymers are environmentally friendly, since they avoid the use of solvents [12].

The main disadvantage of photopolymers, is the limited thickness of laminates that can be cured due to the small penetration depth of UV radiation combined with the photo-masking of the UV polymer by the composite reinforcement. Furthermore, high strength and modulus fibres such as carbon fibre enhance this problem, as they heavily obstruct UV transmission [13].

\section{Manufacture}

For the parabolic flight campaign, both the specimens and the UV curing device were designed and manufactured in-house, using the Applied Mechanics Laboratory facilities. The dimensioning of the specimens was decided after careful consideration of the manufacturing constraints within Novespace's Zero-G aircraft laboratory, the acquisition of materials and similar research performed in literature [14-17].

\subsection{Specimen preparation}

A main type of specimen was produced using double layer woven glass fiber sleeve structure. The glass fiber sleeve used was S-glass 34 tex, had a $\left[ \pm 45^{\circ}\right]$ woven pattern, a base diameter of $45 \mathrm{~mm}$ and a thickness of $0.4 \mathrm{~mm}$. The PEPolyethylene sleeves had also a diameter of $45 \mathrm{~mm}$ and a thickness of $0.1 \mathrm{~mm}$. Both glass fiber and PE sleeves were provided by Fibermax Composites (Volos, Greece). The resin used was acrylic based (>98\% wt $\%$ ) with Phenyl bis $(2,4,6-$ trimethylbenzoyl) phosphine oxide Photoinitiators and was provided by $3 D$ Ink, (Kansas City, USA) without any further purification.

Steps of the manufacturing procedure can be seen in Fig. 1. The Glass-fiber sleeves as well as the two polyethylene sleeves per glass-fiber sleeve were cut at the length of $800 \mathrm{~mm}$. The edges of the glass-fiber sleeve were fixed using tape, to minimize attrition and loose fiber strands. Thus, a tube-like laminate was formed, by enclosing the glass-fiber between the two polyethylene sleeves. A metallic tube mold was placed inside the tube-like laminate, to stretch the laminate into tubular shape. An infusion process was applied, and the specimens were filled with $U V$ resin and concluded to $a V_{f}$ of 0.5 . Then the cylindrical mold was removed. Two short circular cylindrical steel components were placed at the two edges of the composite tube, inside the inner PE sleeve and clamped using a metal strap. The lower steel cylinder was screwed over a base steel plate, while the upper steel cylinder is equipped with one-way air valve.

Finally, the samples were folded using the zigzag folding method [14] and packed for transportation. During resin infusion packing and transportation, the specimens were kept in light-tight storage, to ensure that no polymerization occurred before curing the resin system during the parabolic flight.

\subsection{Specimen curing}

The device used for the curing process of the prepared samples was designed and manufactured in the Applied Mechanics Laboratory, University of Patras, and fulfilled the requirements set by Novespace for the participation in parabolic flights [18]. The device, as shown in Fig. 2a, was mainly partitioned by a UV-light LED source for curing and an oil-less air compressor for the inflation and deployment of the specimens. Inside the curing chamber, a batch of 4 specimens could be inflated and cured simultaneously. Prior and after curing, the specimens were stored in lighttight storage inside the aircraft, to ensure no polymerization occurred outside the curing chamber.

During the parabolic flight campaign of 0-g that lasts for $22 \mathrm{~s}$, the manufactured samples that had been unfolded, initially deployed using an overpressure of 0.5 bar to conclude their cylindrical shape within a time period of $5 \mathrm{~s}$ and afterwards, the UV-light source switched on, providing a $80 \mathrm{~W} / \mathrm{m}^{2}$ quasi-uniform irradiation at $395-405 \mathrm{~nm}$ of 
Fig. 1 Specimen preparation process. a Positioning of glass fiber sleeves on top of inner $P E$ sleeve, $\mathbf{b}$ glass fiber sleeves enclosed between PE sleeves. c mounting of the lower metallic disc and clamp. d Installation of the bottom plate after O-ring placement
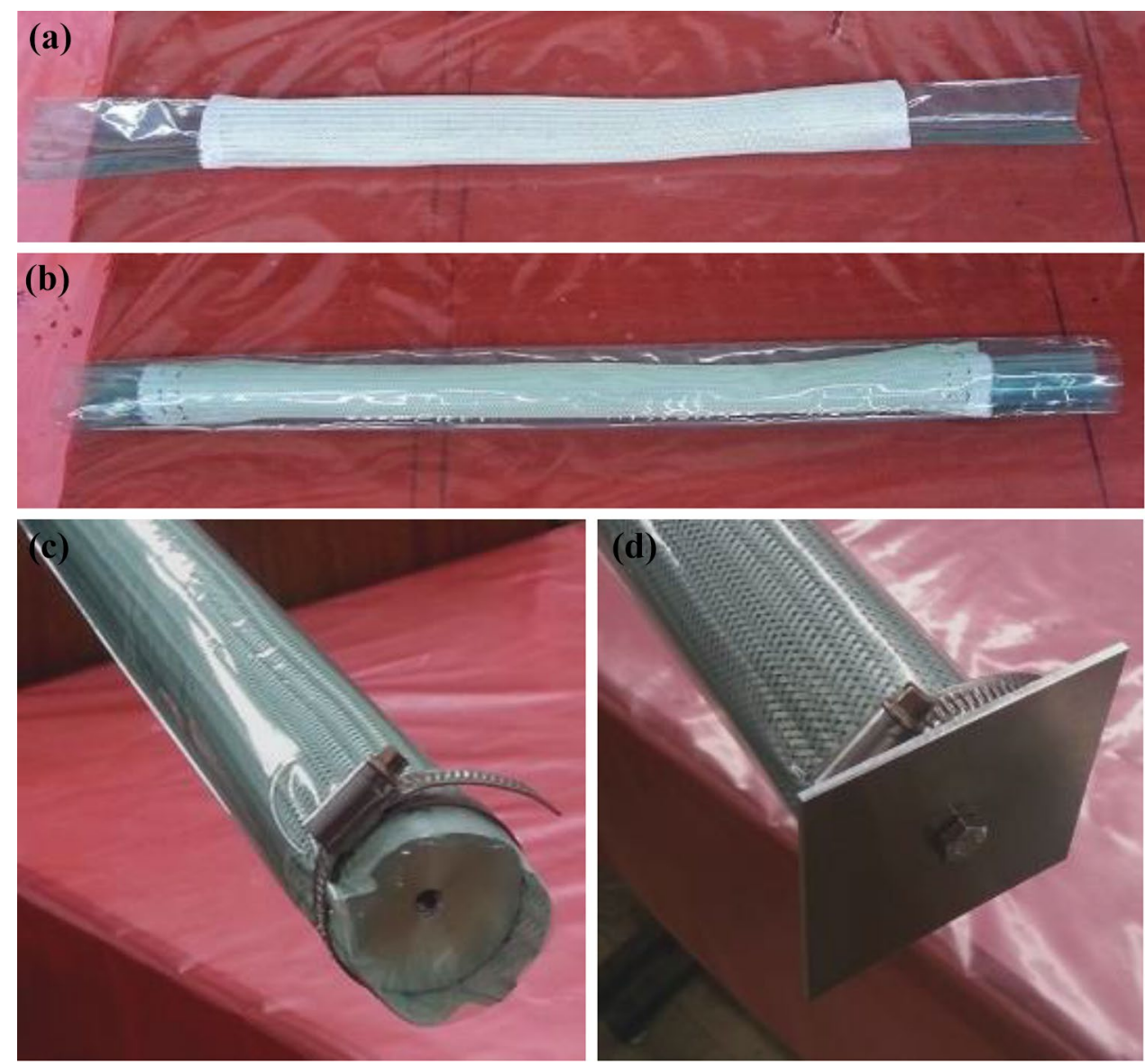

wavelength for the remaining $17 \mathrm{~s}$ of the $0-\mathrm{g}$ phase of the flight. After the first parabola, each batch remained inside the chamber for additional 4 parabolas for further curing only during the $0-\mathrm{g}$ flight phase ( $80 \mathrm{~s}$ approximately). To prevent deflection of the deploying end of the tube specimens during deployment, a sliding plate mechanism was used to fixate the deploying end, as shown in Fig. 2c. Exactly the same curing cycle applied at Laboratory conditions for the manufacturing of the 1-g samples for comparison purposes.

\section{Experiments and testing}

After the parabolic flight campaign, the 0-g specimens were carefully packed and shipped in light-tight storage back to the laboratory, where they were processed together with the 1-g specimens, machined and tested, according to testing standards where possible.

\subsection{Microstructure}

The microstructure of the 1-g and 0-g specimens was analyzed using Scanning Electron Microscopy (LEO SUPRA
35VP). The cross-sections of the composite tubes were examined after cutting of the specimens using a tungsten carbide abrasive wheel. In Fig. 3, the cross-section of a 0-g cured sample is presented. It is shown that the sample has a uniform micro-structure, with the fibers to have a very good impregnation throughout the tube wall thickness. In Fig. 4, the cross-section of 1-g cured sample is shown. The glass fiber reinforcements are again uniformly impregnated by the resin. However, the $0-\mathrm{g}$ specimens show a greater concentration of resin residues bonded on the fibers compared to the 1-g specimens. As a general conclusion based on the SEM findings, the fibers/matrix interface in the 0-g cured composite samples is stronger, based on the cutting surface morphology.

\subsection{Void calculations}

To quantify the surface porosity in the case of $1-\mathrm{g}$ and $0-\mathrm{g}$ cured composites reinforced with double layer woven glass fibers, porosity measurements were performed using post-processing software able to track the contours of the recorded maps. Pictures from various locations of the surface of composite tubes were taken using a Nikon-Optiphot 66 Microscope and analyzed. These images clearly showed 
Fig. 2 a Experiment device rack fixated on board the Zero-G aircraft, $\mathbf{b}$ deployable specimen before curing, $\mathbf{c}$ curing chamber shown from above, with the sliding plate mechanisms prominent

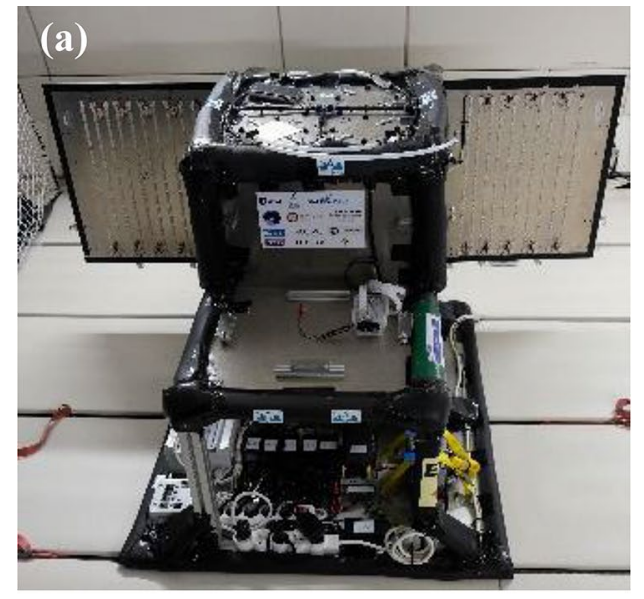

(b)

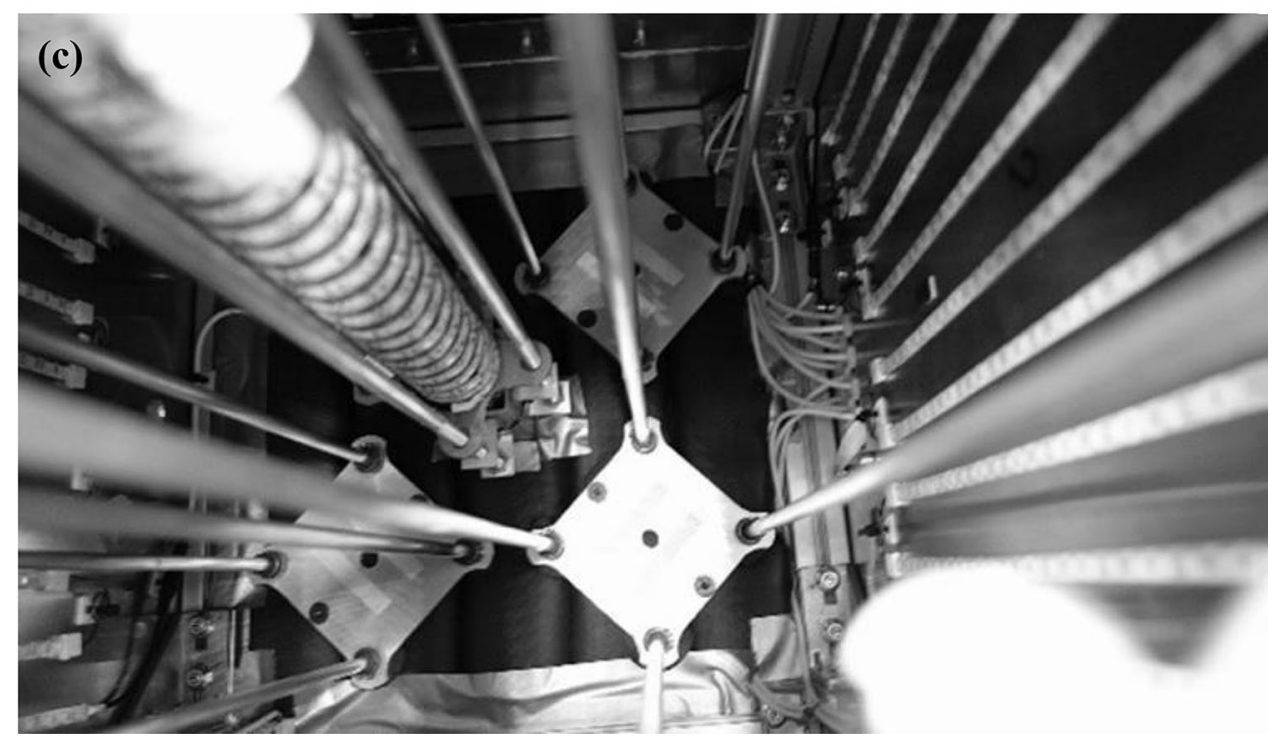

the location, size and evolution of voids on the surface of the deployable composite samples. A typical example of the methodology used is presented in Fig. 5. Initially, the raw image was taken and uploaded into an image analysis software. Then, the areas of surface porosity were outlined and converted into a binary image, where black pixels represent areas of surface porosity. The black pixels in the picture represent areas of porosity, translating thus to a respective percentage of the area being surface porosity. This process was repeated 12 times for each sample and a mean value was extracted for the resulted surface porosity.

In comparison, the average value of the measured samples shows $2.5 \%$ of porosity in $0-\mathrm{g}$ and $12 \%$ in $1-\mathrm{g}$ specimens respectively. This difference in results is consistent with the hypothesis that that in microgravity the surface tension of the liquids dominates over gravity, thus providing a more uniform wettability of the fibers. Because of the air pockets that remained within the PE sleeves, polymerization occurred in the presence of air, leading to the formation of micro-voids that were distributed almost uniformly throughout the surface of the composite deployable samples.

\subsection{DMA: dynamic mechanical analysis}

DMA tests was performed using DMA 983 Du Pont (TA Instruments, Inc., USA) in resonance mode, to determine the glass transition temperature $\left(T_{g}\right)$ of the manufactured composites under $0-\mathrm{g}$ and $1 \mathrm{-g}$ conditions. The heating rate applied was of $2{ }^{\circ} \mathrm{C} / \mathrm{min}$ and the temperature range explored was $25-120^{\circ} \mathrm{C}$. Three samples were used for each material and the dimensions of the specimen were $35 \times 16 \times 1.29 \mathrm{~mm}$. Figure 6 presents typical curves of the Storage modulus versus temperature for both curing conditions. The storage modulus at room temperature was measured at $1.17 \mathrm{GPa}$ for the $1-\mathrm{g}$ and $1.4 \mathrm{GPa}$ for the $0-g$ specimens. Both values are characteristically low and tend to be very close to the resin modulus, however, taking into consideration that the composite samples have a reinforcing $\left[ \pm 45^{\circ}\right]$ woven pattern, the measured properties

\section{SN Applied Sciences}



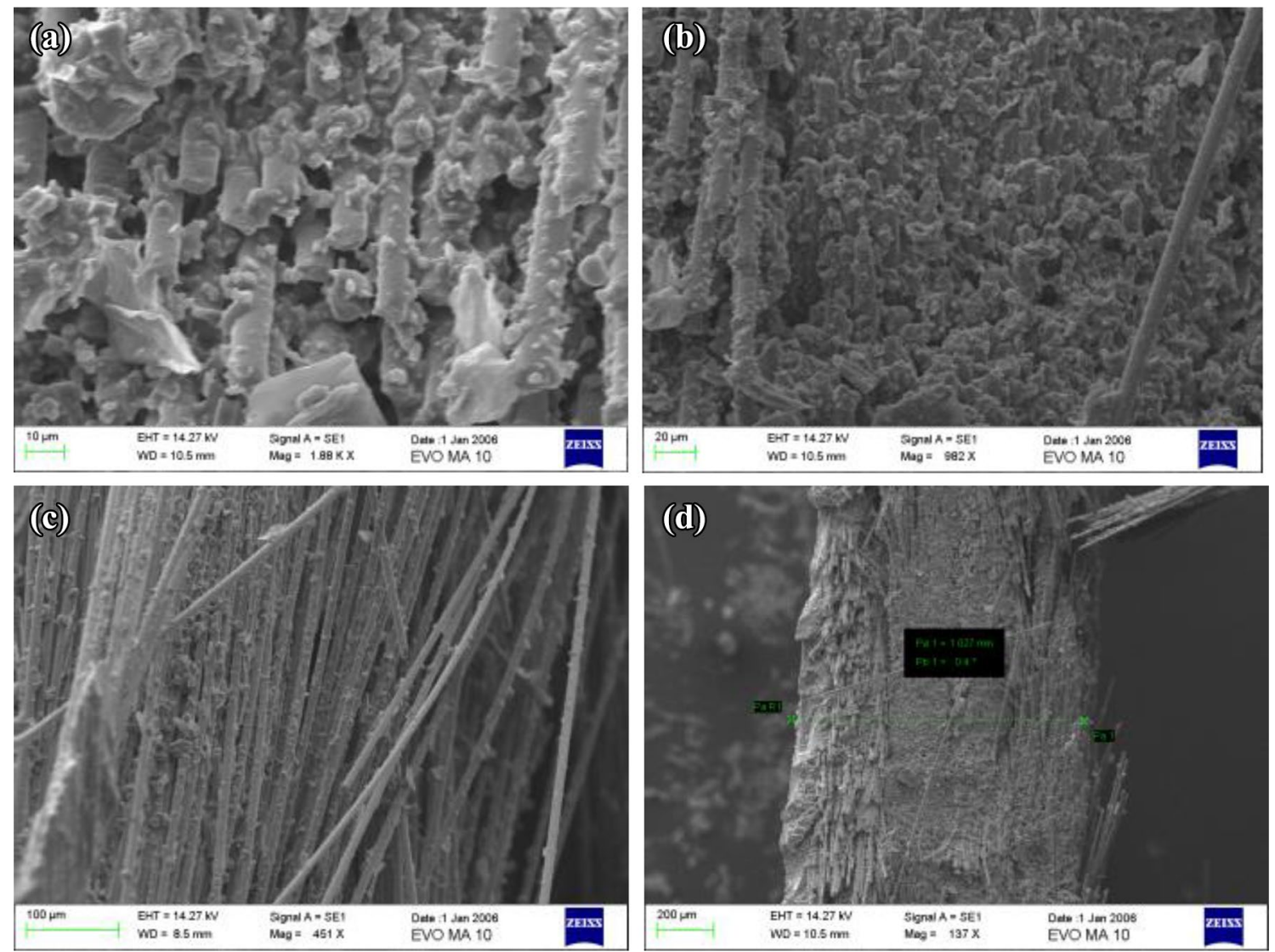

Fig. 3 a-d Microscope imagery of the cross-section 0-g tube specimen wall

are resin driven and the low recorded values are explained. Furthermore, based on the same graphs of Fig. 6 , the glass transition temperature $\left(T_{g}\right)$ was calculated at $80 \pm 2{ }^{\circ} \mathrm{C}$ for the $1-\mathrm{g}$ and $62 \pm 2^{\circ} \mathrm{C}$ for the 0 -g specimens.

\subsection{DSC: differential scanning calorimetry}

The glassy to rubbery phase transition temperature $\left(T_{g}\right)$ of neat resin samples was determined via DSC thermographs. The determined $\mathrm{T}_{\mathrm{g}}$ values are given in Table 1 and were measured at $61.4^{\circ} \mathrm{C}$ and $55.7^{\circ} \mathrm{C}$ for the $1-\mathrm{g}$ and $0-\mathrm{g}$ samples respectively.

As $T_{g}$ describes a dynamic nature effect, discrepancies between the DSC and DMA measure $T_{g}$ values are observed and this a well-known phenomenon [19]. However, the trend remains the same, with the 1-g cured samples to have higher Tg values compared against the $0-g$ cured ones. This difference was expected, as photopolymers in microgravity conditions are affected by gravitysensitive mechanisms [20,21]. Presence of air bubbles containing oxygen, sedimentation of polymer globules and absence of thermal convection, are the main factors which result in a lower degree of polymerization and non-uniform density distribution of the polymer in microgravity conditions [22]. Moreover, the DSC analysis reveals that the resin primary microstructure is at an amorphous state.

\subsection{XRD: X-ray diffusion}

XRD testing was performed for both 0 -g and 1-g specimens to identify the microstructure formation of the polymer in each condition and correlate with the DSC observations. The XRD analysis for neat resin cured in 0-g conditions is given in Fig. $7 a$, where the graph revealed a fully amorphous polymer validating the DSC observation, with a wide peak at $18^{\circ}$ corresponded to the amorphous phase of the resin. In Fig. $7 \mathrm{~b}$, the pattern of a 1-g curing conditions sample is shown, where the wide peak was situated closer to $19^{\circ}$, showing a minimal deviation from the 0-g samples [22].

\subsection{Coupon tensile testing}

For the mechanical tensile testing, the ASTM D 3039/D $3039 \mathrm{M}-00^{\varepsilon 1}$ standard [23] for tension testing of 

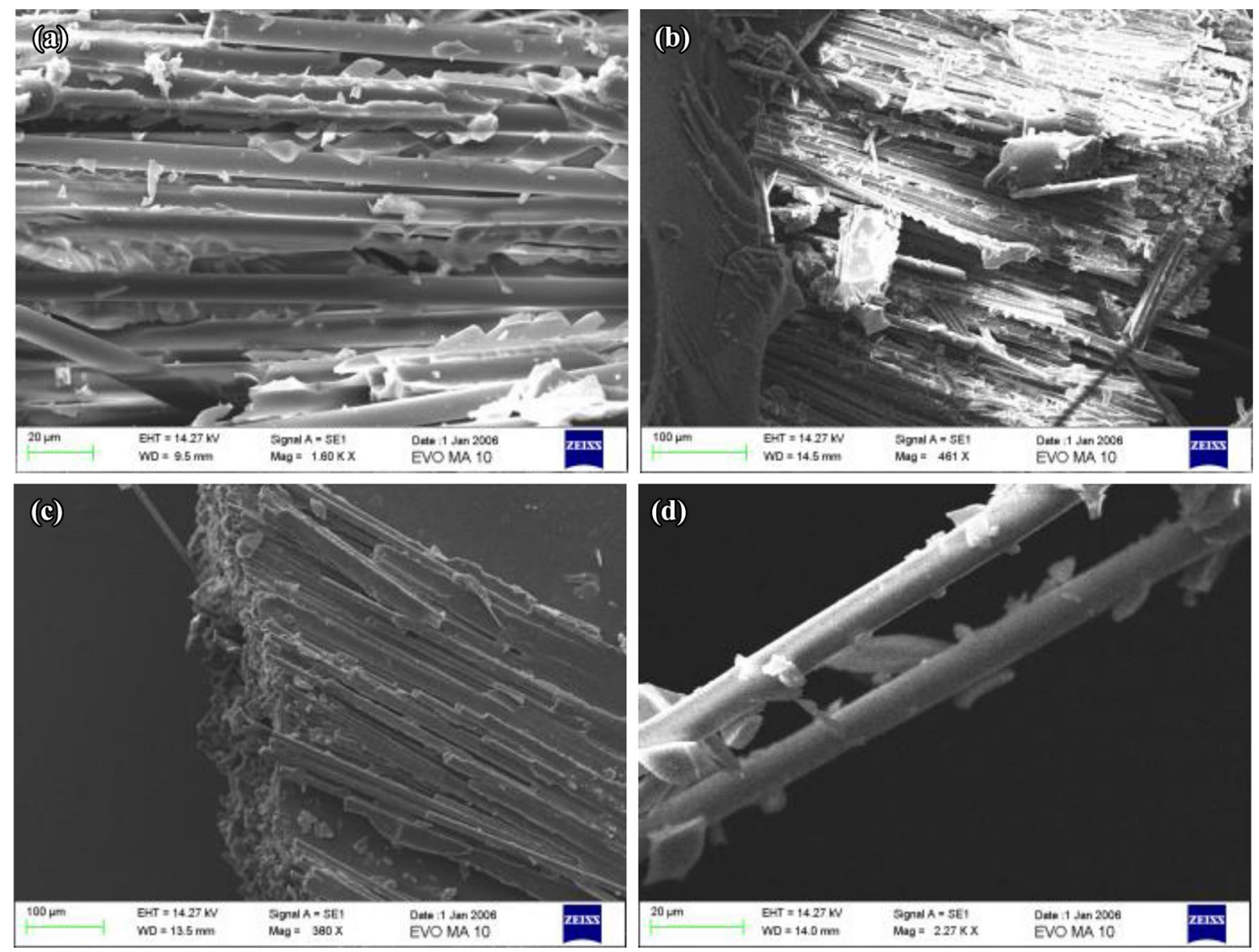

Fig. 4 a-d Microscope imagery of the cross-section 1-g tube specimen wall

Fig. 5 a, $\mathbf{b}$ Sequence of actions used to quantify surface porosity. a Raw image taken and uploaded into image analysis software and $\mathbf{b}$ post-processed image (a)

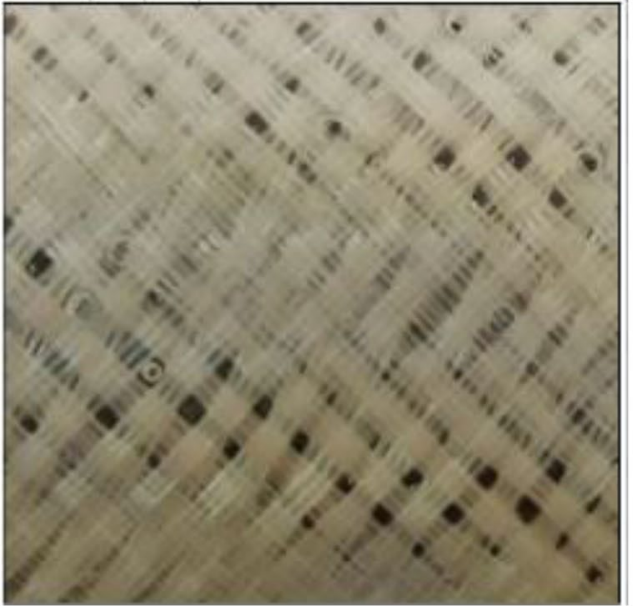

(b)

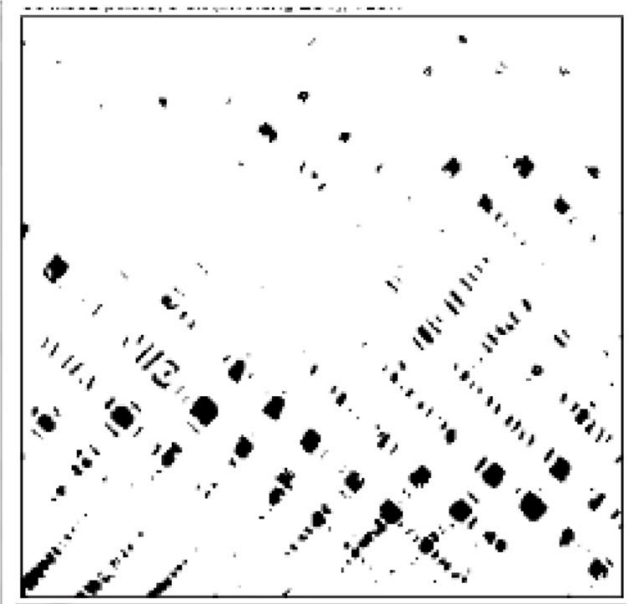

composites was used. The test coupons were cut from several double layered tube specimens in the axial direction at $200 \times 15 \mathrm{~mm}$ dimensions. Seven samples were used for each curing option. The tests were performed at an INSTRON 8872 with a $25 \mathrm{kN}$ loadcell, under controlled temperature and ambient moisture conditions.
The cross-head velocity was $1.5 \mathrm{~mm} / \mathrm{min}$. The test setup is shown in Fig. 8.

Figure 9 shows in a bar chart the tension test results obtained for the $1-\mathrm{g}$ and $0-\mathrm{g}$ curing samples. The results from the 1-g control specimens showed a failure stress of $7.07 \pm 1.43 \mathrm{MPa}$, elastic modulus of $376 \pm 95 \mathrm{MPa}$, ultimate 
Fig. 6 Storage modulus plot of the $0-\mathrm{g}$ and $1-\mathrm{g}$ specimens

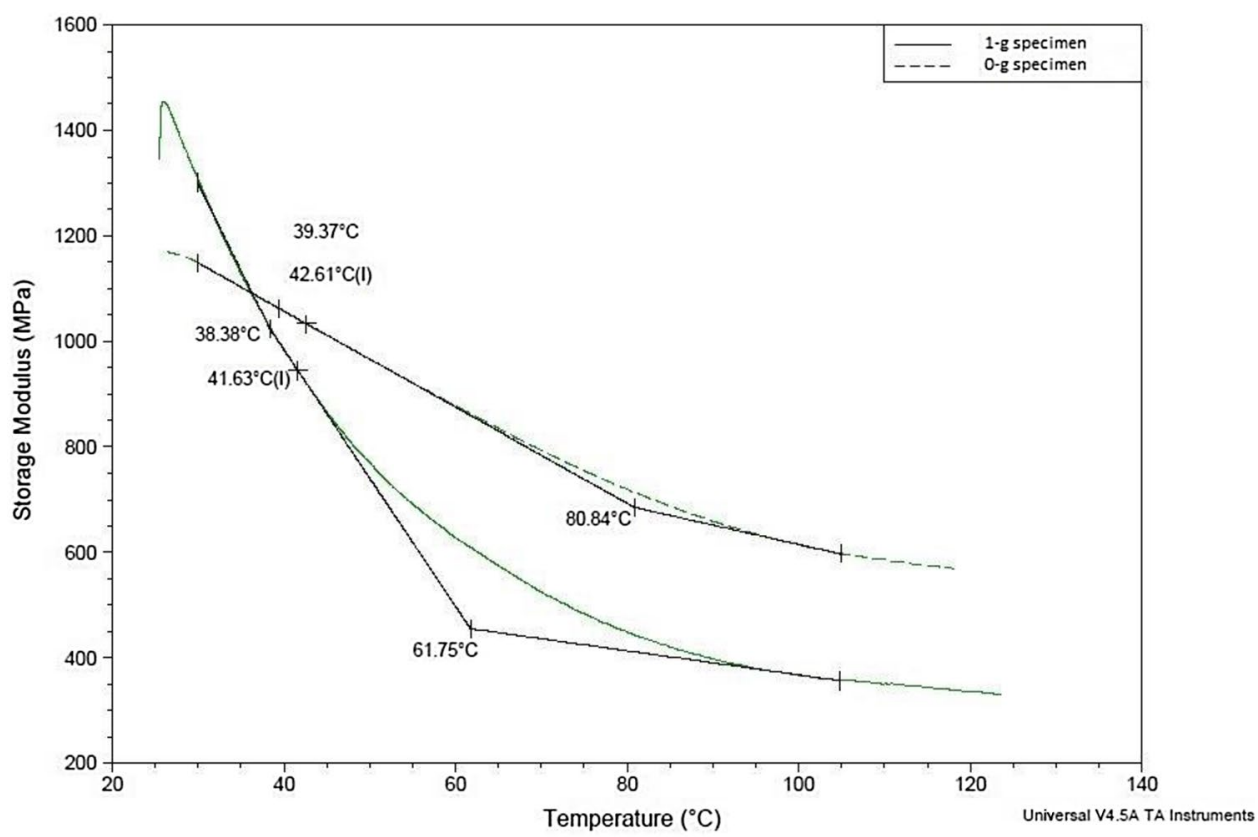

cured specimens with the 1-g control ones, an increase in failure stress of $64 \%$ and in elastic modulus of $20 \%$ are observed. Furthermore, the tests displayed an increase in the ultimate strain to failure of $30 \%$ and finally an increase in energy absorption up to failure of $100 \%$. It is important to notice the high scattering in mechanical properties of the composite samples cured in $0-\mathrm{g}$ conditions.

\subsection{Tube specimen testing}

A total number of two tube specimens (one manufactured and cured at $0-\mathrm{g}$ and the a reference one, manufactured and cured at 1-g) were tested in a cantilever beam

(a)

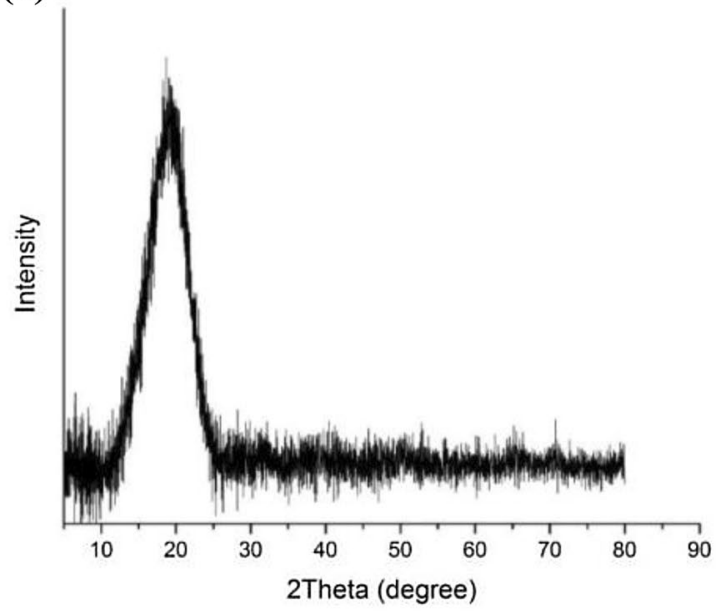

(b)

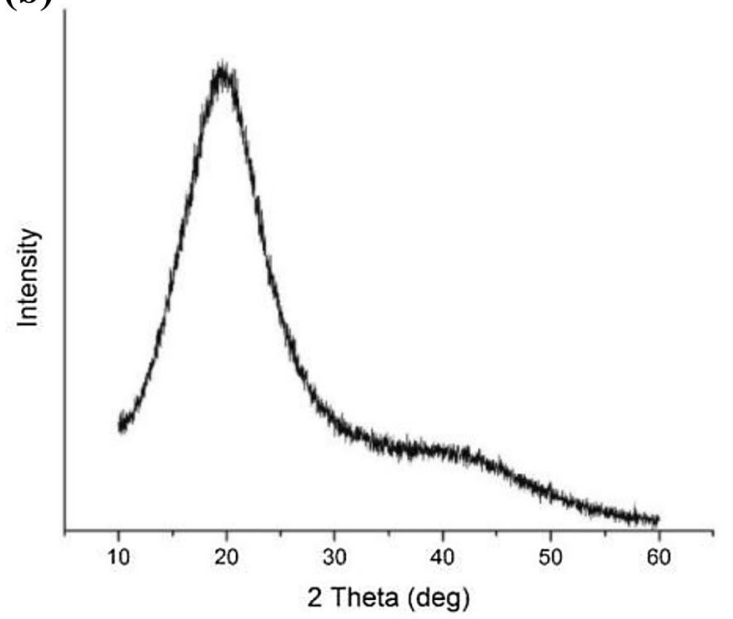

Fig. 7 a XRD plot of the 0-g specimens. $\mathbf{b}$ XRD plot of the 1-g specimens 
configuration, under single point loading in bending applied at the end of the sample as shown in Fig. 10. The load was applied using displacement control at a crosshead velocity of $5 \mathrm{~mm} / \mathrm{min}$. Prior to testing, the tube specimens were stripped of their polyethylene covers. The tube samples had a length of $360 \mathrm{~mm}$, which corresponds to an
L/D beam ratio of 8 . Special jigs were prepared both for the gripping of the samples and the application of the load. Finally, the tubes were fixed on the testing apparatus as shown in Fig. 10.

Both tube specimens were loaded until failure, as shown in Fig. 11. The reference sample failed at a maximum base
Fig. 8 a, b Tensile coupons testing setup. a prior to failure, b post-failure sample
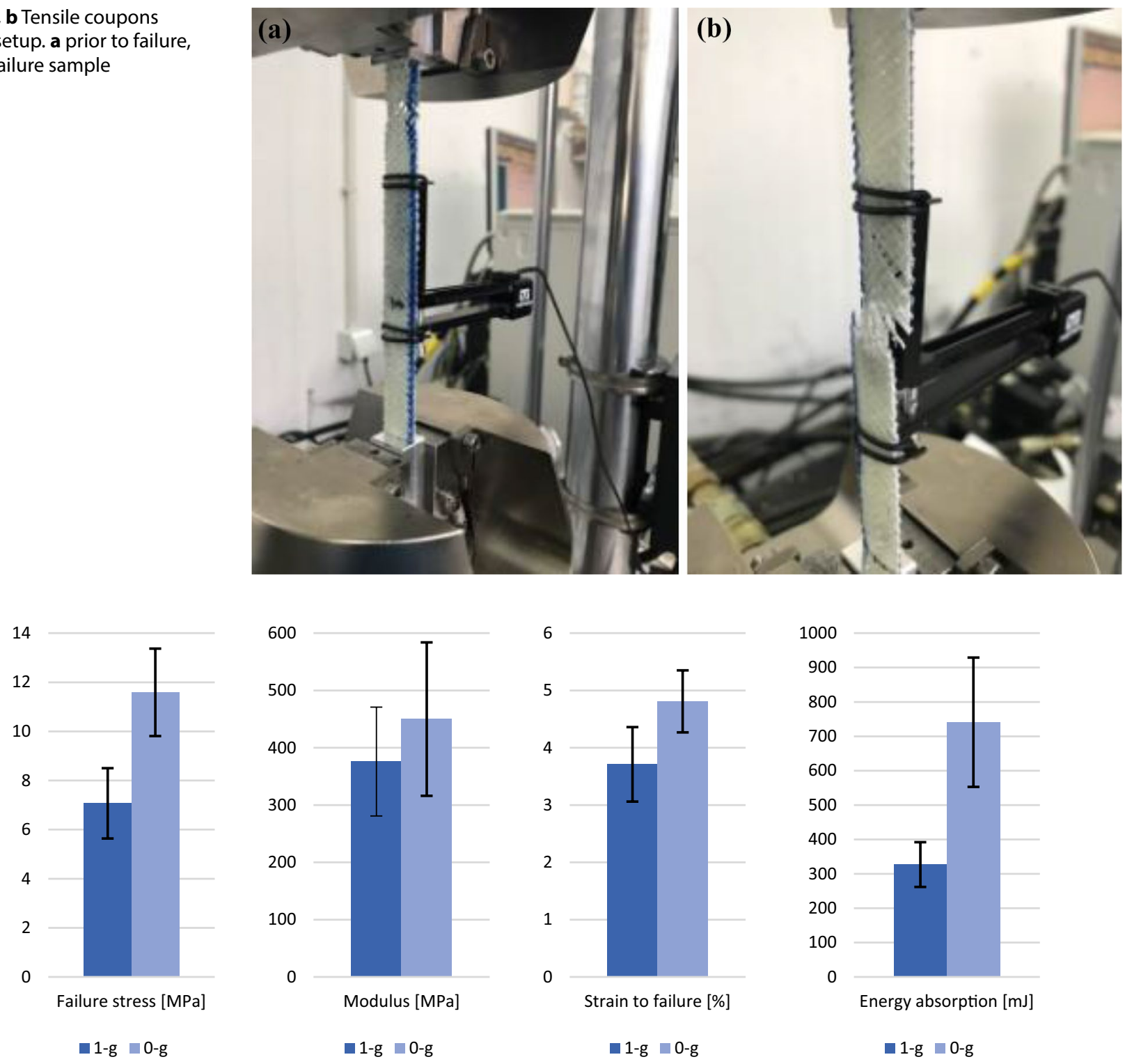
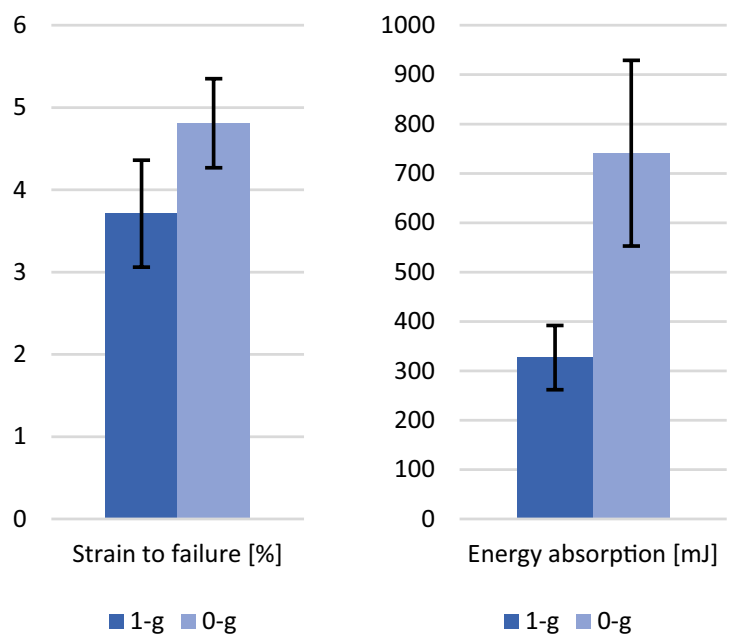

Fig. 9 Tensile mechanical properties comparison of the $1-\mathrm{g}$ and $0-\mathrm{g}$ coupon specimens

Fig. 10 Tube specimen single cantilever test setup

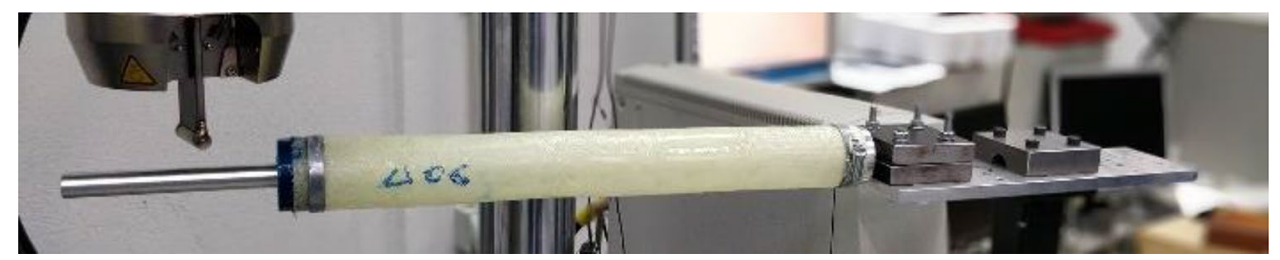


Fig. 11 a, b Failure mode of the tube specimens
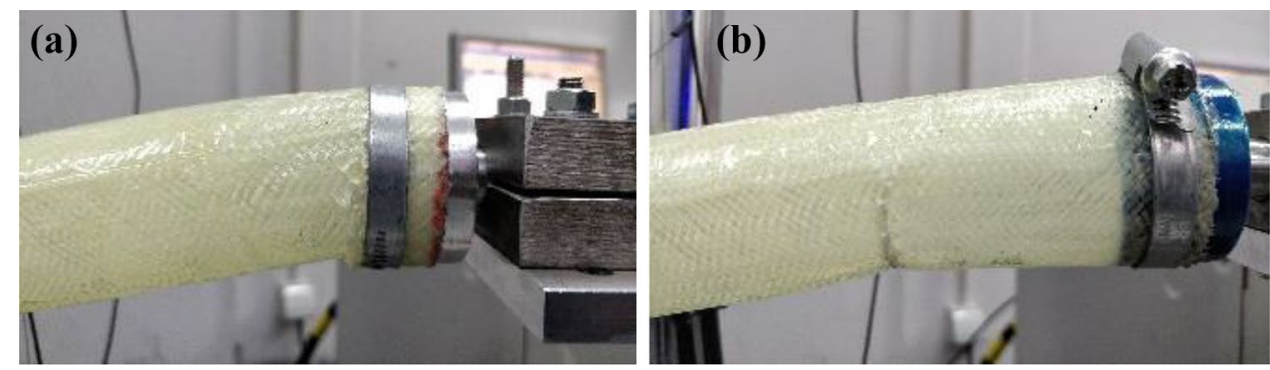

torque of $7.65 \mathrm{Nm}$ and end tip displacement of $24 \mathrm{~mm}$, while the $0-\mathrm{g}$ cured tube failed at a maximum torque of $13.76 \mathrm{Nm}$ and end tip displacement of $64.7 \mathrm{~mm}$. The failure mode of the reference tube was matrix cracking and buckling of the fibres at the base of the beam. In the case of 0-g cured tube the failure mode observed was also matrix cracking and local buckling of the fibers, at a distance of $54 \mathrm{~mm}$ from the base of the beam. In both case the failure of the tube was attributed to geometrical imperfections and/or local microstructural defects at the area of rapture. As it is expected, the bending performance of the 0 -g cure tube is higher due to superior mechanical properties of the material reported earlier.

\section{Conclusion}

The research performed aimed to identify and study the effects of microgravity curing on the properties of fiber reinforced polymer materials. In general, the results showed a superior behavior of the $0-\mathrm{g}$ condition specimens compared to the 1-g control group, with an increase in mechanical properties. However, a noticeable negative effect on the thermal properties behavior of the UV polymer matrix were also observed.

In the microstructure level, in terms of resin-fiber interface impregnation and voids density, the 0 -g specimens showed greater adhesion of resin on the fibers and less void content compared to the $1-\mathrm{g}$ control. This effect is attributed to the domination of the surface tension of the resin in the absence of gravity, leading to a more uniform distribution around the fibers.

Thermal testing of specimens, showed that a decrease in the $T_{g}$ of the $0-g$ condition specimens in comparison with 1-g control. DSC testing produced $\mathrm{T}_{\mathrm{g}}$ values of $55^{\circ} \mathrm{C}$ for the $0-\mathrm{g}$ and $61{ }^{\circ} \mathrm{C}$ for the $1-\mathrm{g}$ specimens, while DMA testing produced increased $\mathrm{T}_{\mathrm{g}}$ of $62^{\circ} \mathrm{C}$ and $80^{\circ} \mathrm{C}$, respectively. Moreover, the DMA testing showed an increase in the storage modulus of the $0-\mathrm{g}$ coupons at $1.4 \mathrm{GPa}$, compared to the $1.17 \mathrm{GPa}$ of the $1-\mathrm{g}$ control.

For the mechanical properties, all tensile tests produced a fairly large scatter of results and the conclusions reached should be taken with caution. The results displayed a greater mechanical performance of the $0-\mathrm{g}$ specimens compared to the $1-\mathrm{g}$ control, with an increase of $60 \%$ in failure stress, $20 \%$ in elastic modulus, $30 \%$ in strain to failure and $100 \%$ in energy absorption to failure. Finally, the tube specimen cantilever, tests showed an increased mechanical behavior of the $0-\mathrm{g}$ specimen, but due to the single specimen testing and difference in failure mode, results were not definitive.

From a greater perspective, the results of this study establish insight on the effect of micro-gravity on the curing of a fibre reinforced UV polymer composite, but further research should be performed. Especially, as the experiment was performed in a micro-gravity environment of an aircraft parabolic flight, the micro-gravity level was limited at a scale of $10^{-2} \mathrm{~g}$, with a g-jitter at an amplitude of $10^{-3} \mathrm{~g}$. These deviations from a $0-\mathrm{g}$ environment are minimal and should not pose any significant deviation in results in this study, but further research should be performed in a more accurate 0 -g environment level and with minimal $\mathrm{g}$-jitter, as in a space orbital experimental facility such as the International Space Station.

For future research, additional cantilever bending testing should be performed on a larger sampling size of tube specimens, to enable statistically valid results to be drawn. In addition, great interest would lie in the investigation of the mechanical behavior of the tubes under various internal pressure conditions, as well perform additional research on the applications of the photopolymer composites, especially in space manufacturing applications, such as ISRU_-In-Situ Resources Utilization and space recycling of structures.

Acknowledgements The authors would like to thank ESA Education, Novespace for accepting the team to participate in the 68th ESA Parabolic Flight Campaign. Additionally, the authors thank ESA Education for funding the team under the auspices of the ESA Fly Your Thesis! Programme. Finally, the authors thank $3 D$ Ink for sponsoring the UV resin and Fibermax Composites for the glass fiber and polyethylene products.

Funding This study was funded by ESA Education for an award of $10 \mathrm{k}$ euros, under the auspices of the Fly Your Thesis! Programme. The funding was awarded to the AML Space Group, University of Patras student team, which includes all the authors of this study. 


\section{Compliance with ethical standards}

Conflict of interest The author(s) declare that they have no competing interests.

Human and animal rights This article does not contain any studies with human participants or animals performed by any of the authors.

Informed consent Informed consent was obtained from all individual participants included in the study.

\section{References}

1. Schwurtx S, Bugby J (1965) Rigidized inflatable solar energy concentrators. Hughes Aircraft Company, Washington, DC

2. Campbell Jr WA, Mamott RS, Park JJ (1985) Outgassing data for selecting spaceraft materials. NASA Goddard Space FlightCenter, Greenbelt, MD

3. Zhou J, Jia S, Fu W, Liu Z, Tan Z (2006) Fast curing of thick components of epoxy via modified UV-triggered frontal polymerization propagating. Mater Lett 176:228-231

4. Bail R, Hong JY, Chin BD (2016) Effect of a red-shifted benzotriazole UV absorber on curing depth and kinetics in visible light initiated photopolymer resins for 3D printing. J Ind Eng Chem 38:141-145

5. Issaa Y, Wattsb DC, Boydc D, Priced RB (2015) Effect of curing light emission spectrum on thenanohardness and elastic modulus of two bulk-fillresin composites. Dent Mater 32:535-550

6. Bova U, Di Stefano R, Pitterà T, Primativo L (2013) Spaghetti beams. In: 6th ESA student parabolic flight campaign

7. Lloro Boada V, Martin Marco Jl, Cabrera Darias CC, Lloro Boada I (2004) Composite photopolymerisation for teeth repairing. In: 7th ESA student parabolic flight campaign

8. Philipp Reiss, Elias Breunig, Philipp Zimmerhakl, Nora Newie, Andreas Zeiner, "Investigating New Space Structures with the FOCUS experiment", ESA REXUS programme, 2011

9. Snyder MP, Dunn JJ, Gonzalez EG (2013) Effects of microgravity on extrusion based additive manufacturing. In: AIAA SPACE 2013 Conference and Exposition, San Diego, California, USA, 10-12 September 2013
10. Jones R (1999) Mechanics of composite materials. CRC Press, Boca Raton

11. Hoyt R, Werkheiser N, Kim T (2016) In-space recycler technology demonstration. NASA Marshall Space Flight Center, Huntsville, $\mathrm{AL}$

12. Zhang J-Y, Windall G, Boyd IW (2002) UV curing of optical fibre coatings using excimer lamps. Appl Surface Sci 186:568-572

13. Schenk M, Viquerat AD, Seffen KA, Guest SD (2014) Review of inflatable booms for deployable space structures-packing and rigidization. J Spacecr Rock 51:762-778

14. Cook AJ, Walker SJI (2015) Experimental research on tape spring supported space inflatable structures. Acta Astronaut 118:316-328

15. Wei J, Tan H, Wang W, Cao X (2014) Deployable dynamic analysis and on-orbit experiment for inflatable gravity-gradient boom. Adv Space Res 55:639-646

16. Katsumata N, Natori MC, Yamakawa H (2013) Analysis of dynamic behavior of inflatable booms in zigzag and modified zigzag folding patterns. Acta Astronaut 93:45-54

17. Lampani L, Gaudenzi P (2010) Numerical simulation of the behavior of inflatable structures for space. Acta Astronaut 67:362-368

18. Novespace (2016) Experiment design guidelines in parabolic flight

19. Patsidis AC, Kalaitzidou K, Psarras GC (2014) Graphite nanoplatelets/polymer nanocomposites: thermomechanical, dielectric, and functional behavior. J Therm Anal Calorim 116:41-49

20. Briskman V, Kostarev K, Levtov V, Lyubimova T, Mashinsky A, Nechitail G, Romanov V (1996) Polymerization under different gravity conditions. ACM Astronautica 39(5):395-402

21. Briskman VA (1999) Gravitational effects in polymerization. Adv Space Res 24(10):1199-1210

22. Zhou G (1998) X-ray diffraction for polymer. China University of Science and Technology Press, Hefei

23. ASTM (2002) D 3039/D 3039M-00 standard test method for tensile properties of polymer matrix composite materials. American Society of Testing and Materials, West Conshohocken, PA

Publisher's Note Springer Nature remains neutral with regard to jurisdictional claims in published maps and institutional affiliations. 